\title{
Death-inducer obliterator 1 (DIDO1) silencing suppresses the growth of bladder cancer cells through decreasing SAPK/JNK signaling cascades
}

\author{
J. LI ${ }^{1,2}$, A. S. WANG ${ }^{1}$, S. WANG ${ }^{1}$, C. Y. WANG ${ }^{1}$, S. XUE ${ }^{1}$, W. Y. LI' ${ }^{1}$, T. T. MA ${ }^{1}$, Y. X. SHAN ${ }^{2, *}$ \\ ${ }^{1}$ Department of Urology, the First Affiliated Hospital of Bengbu Medical College, Bengbu 233004, Anhui, China; ${ }^{2}$ Department of Urology, the \\ Second Affiliated Hospital of Soochow University, Gusu District, Suzhou 215004, Jiangsu, China
}

${ }^{*}$ Correspondence: suhongguan19761@163.com

Received November 15, 2019 / Accepted January 7, 2020

\begin{abstract}
Death inducer obliterator (DIDO) is involved in apoptosis and embryonic stem cell self-renewal. Here, we investigate the effect of DIDO1 on bladder cancer cells and clarify the underlying molecular mechanism. Bladder cancer tissues and cell lines (T24, ScaBER, 5637), as well as normal bladder epithelial cells (SV-HUC-1), were used to measure the levels of DIDO1 mRNA and protein by qRT-PCR and western blot, respectively. The results indicated that DIDO1 was highly expressed in bladder cancer tissues and cell lines. And the expression of DIDO1 in T24 and 5637 cells was higher than that in ScaBER and SV-HUC-1 cells. The expression of DIDO1 was knocked down in T24 and 5637 cells by infection with shDIDO1-1 and shDIDO1-2 lentivirus. The growth of T24 and 5637 cells was monitored using Celigo, MTT assays, and colony formation assay. Apoptosis was examined by flow cytometric analysis. The effect of DIDO1 knockdown on tumorigenesis of T24 xenograft tumors was determined in nude mice. Reduction of DIDO1 mRNA resulted in reduced proliferation, decreased cell colony formation, increased apoptosis in vitro, and inhibited tumorigenesis in vivo. Furthermore, we identified signaling molecules involved in stress and apoptosis using the PathScan Antibody Array Kit and western blot. The depletion of DIDO1 significantly decreased the levels of phosphorylated SAPK/JNK, and Chk1/2, as well as the upregulating cleaved Caspase-7 expression. These results indicated that the potential mechanism of DIDO1 action might involve SAPK/JNK signaling cascades.
\end{abstract}

Key words: bladder cancer, death inducer obliterator DIDO1, cell proliferation, SAPK/JNK signaling cascades

Nearly 430,000 new cases of bladder cancer are diagnosed each year globally [1]. This disease is the most frequent malignant tumor involving the urinary tract and has a poor prognosis and high recurrence rate [1]. In middle-aged and elderly men, bladder cancer is the second most common malignancy next to prostate cancer [2]. Furthermore, the incidence and mortality of bladder cancer have gradually increased in the last two decades due to the increased proportion of elderly people in the population. Transurethral bladder resections alone and in combination with chemotherapy have been applied in the treatment of bladder cancer. However, the explorations of new and effective diagnostic and therapeutic strategies are urgent $[3,4]$. Some molecular alterations including deletion, mutation, and aberrant methylation of genes may play a critical role in the occurrence and development of bladder cancer. These changes can be exploited to predict the prognosis of bladder cancer and applied in the creation of individualized therapies [5].

Death inducer obliterators are expressed in all tissues and comprises of three alternatively spliced isoforms
(DIDO1, DIDO2, DIDO3) [6, 7]. Death inducer obliterator 1 (DIDO1), also known as death-associated transcription factor 1 (DATF-1), was the smallest variant, first identified in WOL-1 cells [6]. The amino acid sequence of DIDO1 contains a glutamine-rich region, 2 zinc finger motifs, an acidic sequence part from a nuclear localization signal (NLS) in the N-terminus, and a lysine-rich sequence in the C-terminus [6]. In the cytoplasm of normal cells, DIDO1 phosphorylation on serine/threonine is present at a very low level. After activation, DIDO1 translocates to the nucleus to trigger apoptosis in WOL-1 cells [6]. Although there have been evidence for its involvement in apoptosis and embryonic stem cell self-renewal, the function of DIDO1 is still poorly understood [6]. Additionally, no functional information has been available so far about DIDO1 in human bladder cancer.

In this study, we examined the expression of DIDO1 in bladder cancer tissues and cell lines 5637, ScaBER, and T24, and investigated the effect of knockdown of DIDO1 by DIDO1-shRNA on cell proliferation and apoptosis in T24 
and 5637 cells. Our results indicated that DIDO1 was highly expressed in bladder cancer tissues and cell lines. The knockdown of DIDO1 inhibited the proliferation of bladder cancer cells both in vitro and in vivo. The reduction of DIDO1 also increased the apoptosis of bladder cancer cells. This suggested that DIDO1 may be a novel target involved in the treatment of bladder cancer.

\section{Materials and methods}

Human samples. Samples of bladder tumor and non-tumor were collected from 20 inpatients in the Department of Urology, the First Affiliated Hospital of Bengbu Medical College (Bengbu, China) from April 2017 to November 2018. Consent was acquired from all subjects and the experimental protocols were approved by the Ethics Committee of the First Affiliated Hospital of Bengbu Medical College and followed the Declaration of Helsinki. The age of the patients at diagnosis ranged from 30 to 63 years old, with a median age of 52 years old.

Preparation of lentiviral vector. Small hairpin RNAs (shRNAs) targeting the DIDO1 sequence (GenBank no. NM_033081) (shDIDO1 lentivirus) and a non-silencing sequence were ligated into the pGCL-GFP-lentiviral vector (Genechem, Shanghai, China). The plasmids used were pGCSIL-GFP-shDIDO1-1 and pGCSIL-GFP-shDIDO1-2 for specific interfering of DIDO1 and pGCSIL-GFP-NC was used as the control. Sequences used were as follows: the specific sequences for DIDO1 (all isoform of DIDO1) silencing: 5'-GGATGAGACTCATTCAGAA-3' (shDIDO1-1), 5'-TTGTTGGTCCAGTTTCGCC-3' (shDIDO1-2), and scramble silencing sequence as control: 5'-AATTCTCCGAACGTGTCACGT-3'. Human bladder cancer cell lines were infected with shDIDO1-1, or shDIDO1-2, or shCtrl lentivirus; the efficiency of shRNA interference was detected by western blot.

Cell culture, generation of lentivirus, and infection of bladder cancer cell lines. Bladder cancer cell lines T24, ScaBER, 5637, human normal bladder epithelial cell line SV-HUC-1, and human kidney epithelial cell line 293T were obtained from Shanghai Cell Bank of Chinese Academy of Science and routinely cultured in Dulbecco's Modified Eagle's Medium (DMEM) (Invitrogen, Carlsbad, CA, USA) containing $10 \%$ fetal bovine serum, $100 \mathrm{IU} / \mathrm{ml}$ penicillin and $100 \mu \mathrm{g} / \mathrm{ml}$ streptomycin (Sigma) and incubated in an incubator with $5 \% \mathrm{CO}_{2}$ and $95 \%$ humidity at $37^{\circ} \mathrm{C}$.

$293 \mathrm{~T}$ cells were seeded into 6-well plates with a density of 2000 cells/well for lentiviral infection. Plasmids containing shRNA targeting DIDO1 and control shRNA were transfected into 293T cells using Lipofectamine 2000 (Invitrogen, Carlsbad, CA, USA) to generate lentivirus. Infected cells were measured by counting green-colored cells using fluorescence-imaging microscopy (Olympus, Tokyo, Japan), as well as bladder cancer cell lines for determining transfection efficiency. Then, human bladder cancer cell lines T24 and 5637 were transfected by shDIDO1-1, shDIDO1-2, or shCtrl lentivirus for further analysis. Briefly, shDIDO1 or shCtrl plasmids and packaging vectors were cotransfected into $293 \mathrm{~T}$ cells to produce the respective lentivirus. $72 \mathrm{~h}$ post-transfection, the supernatants containing infective lentiviral particles were concentrated by ultracentrifugation at $25,000 \mathrm{rpm}$ for $1.5 \mathrm{~h}$ and resuspended in PBS. For lentiviral infection, T24 and 5637 cells were cultured in 6-well plates with a density of $5 \times 10^{4}$ cells per well and infected by either shDIDO1-1, shDIDO1-2, or shCtrl lentiviruses in the presence of $5 \mu \mathrm{g} / \mathrm{ml}$ of polybrene (Forevergen). Cells were exposed to $2 \mu \mathrm{g} / \mathrm{ml}$ puromycin for $10-15$ days to get stable infected DIDO1-knockdown and scrambled shRNA cells.

Expression of DIDO1 in 5637 and T24 cells measured by quantitative real-time PCR. Total RNA was isolated from T24, ScaBER, and 5637 bladder cancer cells using Trizol reagent (Invitrogen, Carlsbad, CA, USA) and used to synthesize cDNA via reverse transcription using RevertAid ${ }^{\text {mit }}$ First Strand cDNA Synthesis Kit (cat no. K1622, MBI Fermentas, Lithuania) according to the manufacturer's instructions. Firstly, $1 \mu \mathrm{g}$ of oligo dT was mixed with $2 \mu \mathrm{g}$ of total RNA and $\mathrm{ddH}_{2} \mathrm{O}$ to $9 \mu \mathrm{l}$ and was incubated at $70^{\circ} \mathrm{C}$ for $10 \mathrm{~min}$, followed by incubation on ice-water for primer annealing. Then, $4 \mu \mathrm{l}$ of $5 \times$ RT buffer, $2 \mu \mathrm{l}$ of $10 \mathrm{mM}$ dNTPs, $0.5 \mu \mathrm{l}$ of RNasin, $3.5 \mu \mathrm{l}$ of $\mathrm{ddH}_{2} \mathrm{O}$, and $1 \mu \mathrm{l}$ of MMV-RTase were added and incubated at $42{ }^{\circ} \mathrm{C}$ for $60 \mathrm{~min}$. Finally, the mixture was incubated at $70^{\circ} \mathrm{C}$ for $10 \mathrm{~min}$ to inactivate MMV-RTase. The expression level of DIDO1 mRNA was measured by qPCR using a SYBR master mixture (Takara, Dalian, China) on a Light Cycler 480 device (Roche, Switzerland).

PCR reactions were performed as follows: denaturation at $95^{\circ} \mathrm{C}$ for $5 \mathrm{~min}$, then 40 cycles of $95^{\circ} \mathrm{C}$ for $10 \mathrm{~s}$, and $60^{\circ} \mathrm{C}$ for $20 \mathrm{~s}$. Each sample was assessed in triplicate. Specific primer sequences were used as follows: DIDO1 (forward 5'-CGCCAGCCTCACAACAAC-3' and reverse 5'-ATCAGCATCTCCAGGTCTCC-3'), and GAPDH (forward 5'-TGACTTCAACAGCGACACCCA-3' and revere 5'-CACCCTGTTGCTGTAGCCAAA-3'). Changes in gene expression were analyzed using the $2^{-\Delta \Delta C \mathrm{CT}}$ method [8].

shRNA knockdown efficiency detection. Human embryonic kidney $293 \mathrm{~T}$ cells or human bladder cancer cells $\left(5 \times 10^{4} /\right.$ well $)$ were seeded into 6 -well plates and then transfected with the plasmids shDIDO1-1, shDIDO1-2, or shCtrl. Cells were incubated at $37^{\circ} \mathrm{C}$ in an incubator containing $5 \% \mathrm{CO}_{2}$ for 2 days. Then the appropriate lentiviral particle solution $(5 \mu \mathrm{l}$ of the virus per well) was added $(\mathrm{MOI}=5)$. Three days after infection, GFP expression from the vector was detected under a fluorescence microscope (IX71, Olympus, Tokyo, Japan) to determine the infection efficiency. Cells were collected when the efficiency of the infection exceeded $50 \%$ and then stored for the further analysis described below.

Cell proliferation assay. Human bladder cancer T24 and 5637 cells were infected with shDIDO1-1, shDIDO1-2, and non-silencing sequences (shCtrl), and seeded into 96-well plates with $2 \times 10^{3}$ cells and $100 \mu \mathrm{l}$ medium/well. Cells were 
then incubated at $37^{\circ} \mathrm{C}$ in an incubator containing $5 \% \mathrm{CO}_{2}$ for $24 \mathrm{~h}$ and quantified autonomously once a day for 5 days using the Cellomics ArrayScan VTI system (Thermo Fisher Scientific, Rockford, IL, MA, USA). Cell growth curves were generated for each condition. Meanwhile, proliferation was also measured at 1, 2, 3, 4, and 5 days after seeding by performing an MTT assay. After the addition of $20 \mu \mathrm{l}$ methylthiazoletetrazolium solution (MTT, $5 \mathrm{mg} / \mathrm{ml}$ ) into each well, plates were incubated for $4 \mathrm{~h}$ at $37^{\circ} \mathrm{C}$. Then, the media in each well was removed and $150 \mu$ l of dimethyl sulfoxide (DMSO) was added into each well to achieve the dissolution of crystals. After that, the plates were incubated for $10 \mathrm{~min}$ at room temperature and then the absorbance was measured at 490/570 nm using Enzyme standard instrument (Thermo Fisher Scientific, USA).

Cell colony formation assay. A cell colony formation assay was conducted 5 days after the infection of T24 and 5637 cells with shDIDO1-1, shDIDO1-2, and non-silencing sequences. Cells were seeded into 6-well plates with a density of 1,000 cells/well and cultured in DMEM containing $10 \%$ FBS for 14 days. Then the cells were washed twice with PBS and fixed with $4 \%$ paraformaldehyde for $30 \mathrm{~min}$. $1 \times$ PBS was added into each well and the plates were stained with $500 \mu \mathrm{l}$ of Giemsa for $10 \mathrm{~min}$. After washing three times with $\mathrm{dd}_{2} \mathrm{O}$, the plates were photographed with a digital camera.

Western blot analysis. Cells were lysed and homogenized in ice-cold lysis buffer. Homogenates were then centrifuged at $13,000 \mathrm{rpm}$ for $15 \mathrm{~min}$ at $4^{\circ} \mathrm{C}$ to extract total protein. The concentrations of proteins in supernatants were measured using Modified BCA Protein Assay Kit (cat no. C503051, Sangon Biotechnology, China) and electrophoretically separated in $12 \%$ sodium dodecyl sulfate-polyacrylamide gel electrophoresis (SDS-PAGE), and transferred onto PVDF membranes. Membranes were incubated overnight at $4^{\circ} \mathrm{C}$ in blocking buffer containing skim milk (5\%) to block non-specific sites. After that, rabbit polyclonal antibody specific for DIDO1 (1:2000, cat no. ab19029, Abcam), antiPhospho Serine/Threonine Chk1/Chk2 substrate antibody (1:500, cat no. ab131023, Abcam), anti-caspase-7 antibody ([E22], 1:1000, cat no. ab25900, Abcam), anti-JNK1 antibody (1:1000, cat no. ab199380, Abcam), anti-JNK1 (phosphor T183) antibody (1:1000, cat no. ab47337, Abcam), and a monoclonal antibody specific for GAPDH (1:5000, cat no. sc-32233, Santa Cruz Biotechnology) were added. Membranes were then rinsed 3 times with TBST buffer and incubated with secondary antibodies conjugated to horseradish peroxidase $(1: 10000$, cat no. sc-2005, Santa Cruz Biotechnology) at room temperature for $1 \mathrm{~h}$. After washing the membrane with TBST three times at room temperature, western blots were visualized with luminescence reagent (Bio Basic Inc., Canada).

Detection of apoptosis using flow cytometry. To determine the effects of DIDO1 expression on cell apoptosis at an early stage, human bladder cancer T24 and 5637 cells were infected with shDIDO1-1, shDIDO1-2, or a control. Cells $\left(5 \times 10^{5}\right)$ were harvested and washed using D-Hanks ( $\left.\mathrm{pH} 7.2\right)$. Then, cells were washed two times using $1 \times$ binding buffer and stained with Annexin V-APC (cat no. 88-8007, eBioscience, Shanghai, China) while protected from light at $25^{\circ} \mathrm{C}$ for $15 \mathrm{~min}$. After that, the stained cells were analyzed by flow cytometry.

Determination of cleaved caspase-7 activity. The activity of cleaved caspase-7 was measured by the CaspaseGlo-7 assay kit according to the manufacturer's instructions (Promega, Shanghai, China). Briefly, protein concentrations of the cell homogenates in each group were determined and equal amounts of the homogenates were subjected to the enzymatic assay following the standard protocol.

PathScan Stress and Apoptosis Signaling Antibody Array analysis. Protein lysates from T24 cells transfected with shDIDO1-1 or shCtrl lentivirus were assayed by the PathScan ${ }^{\circledast}$ Stress and Apoptosis Signaling Antibody Array Kit (catalog no. 12923, Cell Signaling Technologies (CST), MA, USA) according to the manufacturer's instructions. The kit contains 19 signaling molecules involved in the regulation of stress response and apoptosis, and the array target map used can be found on the manufacturer's homepage (http://www.cst-c.com.cn/products/12856.html). Briefly, T24 cells $\left(2 \times 10^{6}\right)$ transfected with shDIDO1 or shCtrl lentivirus were washed using pre-cooling $1 \times \mathrm{PBS}(\mathrm{pH} 7.2)$ twice and lysed using lysate buffer (cat no. 7018, CST) on ice. Protein concentration was quantified using the Modified BCA Protein Assay Kit (Sangon Biotech, Shanghai, China), and adjusted at the concentration of $0.5 \mathrm{mg} / \mathrm{ml} .100 \mu$ Array Blocking Buffer was added into each well of the slides and incubated for $15 \mathrm{~min}$ at room temperature. After decanting Array Blocking Buffer, $75 \mu \mathrm{l}$ of lysates was added into each well and the slides were incubated at $4^{\circ} \mathrm{C}$ overnight. After that, slides were washed five times using $1 \times$ Array Wash Buffer $(100 \mu \mathrm{l} /$ well $)$. Then, $75 \mu \mathrm{l}$ of $1 \times$ Detection Antibody Cocktail was added into each well followed by incubation for $60 \mathrm{~min}$ at room temperature. After washing with $1 \times$ Array Wash Buffer $(100 \mu \mathrm{l} /$ well $)$ five times, $75 \mu \mathrm{l}$ of $1 \times$ HRP-linked Streptavidin was added into each well following the incubation for $30 \mathrm{~min}$ at room temperature. Slides were washed 4 times for $5 \mathrm{~min}$ with $1 \times$ Array Wash Buffer $(100 \mu \mathrm{l} /$ well $)$ and covered with LumiGLO $\% /$ Peroxide reagent. Then, the slides were imaged using a ChemiScope5300 Pro Integrated chemiluminescence imaging system (CLiNX Science Instruments, Shanghai, China) and the signal from each spot was analyzed. Each experiment was repeated three times.

Xenograft tumors in nude mice. Each of the four weeks old female BALB/c nude mice was subcutaneously injected at a single site with $200 \mu \mathrm{l}$ of T 24 cells $\left(1 \times 10^{6}\right.$ cells $\left./ \mathrm{ml}\right)$ which were successfully transfected with either the shDIDO1-2 or the shCtrl lentivirus. The mice were reared until the tumor was visible by the naked eye (on day 20 , referred to as day 0 ). The tumor volumes were measured on $0,4,7,11$, and 14-day after 20 days of inoculation. Animals were sacrificed 5 weeks after inoculation. The average tumor weight was determined 
by physical measurement of the excised tumor at the time of sacrifice. The tumor sizes were measured using a caliper. The animal experiments were approved by the Institutional Animal Care and Use Committee of the First Affiliated Hospital of Bengbu Medical College (No. 2017-089).

TUNEL assay. One Step TUNEL Apoptosis Assay Kit (Beyotime, Shanghai, China) was used to evaluate cell apoptosis. The cell slides were fixed with $4 \%$ paraformaldehyde for $30 \mathrm{~min}$ and then rinsed twice with PBS. The cell slides were incubated with PBS containing $0.1 \%$ Triton X-100 for $2 \mathrm{~min}$ on ice and rinsed twice with PBS. The cells were then incubated with TUNEL detection solution (composed of TdT enzyme and FIFC-dUTP) in dark for $1 \mathrm{~h}$ at $37^{\circ} \mathrm{C}$. Finally, DAPI was added to stain the nucleus. The results were observed by a fluorescence microscope (Olympus, Tokyo, Japan).

Statistical analysis. Data were expressed as the mean \pm standard deviation (SD). All experiments were repeated three times except xenograft tumors. Differences between two groups were analyzed by one-way analysis of variance (ANOVA) using the least significance difference (LSD) and t-test. The analysis was performed using SPSS software version 16.0 (SPSS Inc., Chicago, IL, USA). A p-value $\leq 0.05$ was considered statistically significant.

\section{Results}

Expression of DIDO1 in bladder cancer samples and cell lines. To investigate the expression of DIDO1 in human bladder cancer and matched adjacent non-tumor (referred to as normal) tissues, 20 samples were selected randomly to analyze the level of DIDO1 mRNA using qRT-PCR. The results showed that the levels of DIDO1 mRNA in cancer tissues were significantly higher than in normal tissues $(\mathrm{p}<0.01$; Figure $1 \mathrm{~A})$. Furthermore, the expression of DIDO1 mRNA was detected in bladder cancer cell lines T24, ScaBER, 5637, and human normal bladder epithelial cell SV-HUC-1 by qRT-PCR. The expression levels of DIDO1 mRNA in 5637 and T24 cell lines were higher than those in the SV-HUC-1 and ScaBER cell lines $(\mathrm{p}<0.01$; Figure $1 \mathrm{~B})$ and these were confirmed by western blot (Figure 1C). Therefore, the 5637 and T24 cell lines were chosen for further experiments in order to understand the effect of DIDO1 knockdown.

Expression of DIDO1-shRNA reduces the expression of DIDO1. The expression of GFP was assessed using fluorescence microscopy to determine the efficiency of lentiviral infection. The high fluorescent expression was observed in T24 and 5637 cells transfected with shCtrl and reduced in shDIDO1-1/shDIDO1-2 transfected cells (Figure 1D). The result showed that stable cell lines expressing DIDO1 were generated. Expression of DIDO1 (protein and mRNA) in cells transfected with shDIDO1-1 or shDIDO1-2 was significantly reduced compared with control cells $(\mathrm{p}<0.01$; Figures $1 \mathrm{D}, \mathrm{E})$. Furthermore, the result of western blot analysis indicated that the levels of DIDO1 protein in DIDO1-1-shRNA or
DIDO1-2-shRNA expressing-cells were decreased compared with control cells (Figure 1F).

The knockdown of DIDO1 by shRNA inhibits the growth of bladder cancer cells. The effect of DIDO1 expression on the proliferation of bladder cancer cells was estimated using T24 and 5637 cells expressing DIDO1-1-shRNA or DIDO1-2-shRNA. We detected a significant inhibition of proliferation 4 and 5 days after seeding T24 and 5637 cells expressing DIDO1-1-shRNA or DIDO1-2-shRNA compared to control cells $(p<0.01$; Figure $2 A, 2 B)$. This suggested that the downregulation of DIDO1 inhibited the proliferation of bladder cancer cells.

To further demonstrate the inhibitory effect of shDIDO1 on cell growth, an MTT assay was also carried out to monitor cell viability. As described above, T24 and 5637 cells were infected with lentiviral shDIDO1-1, shDIDO1-2 or shCtrl, respectively, and the viability profile was analyzed using an MTT assay each day for 5 days. The results also showed that knockdown of DIDO1 significantly decreased cell viability after $48 \mathrm{~h}$ of transfection with shDIDO1 lentivirus and the decreased cell viability profiling was continued in the following 3 days compared with those in shCtrl group $(\mathrm{p}<0.01$; Figure 2B). Taken together, these results suggested that DIDO1 promotes bladder cancer cell progression via accelerated cell growth and proliferation.

To further examine the effect of DIDO1 downregulation by DIDO1-shRNAs on the growth of bladder cancer cells, cell colony formation was observed. The number of colonies formed was significantly decreased in T24 and 5637 cells expressing DIDO1-shRNAs compared with control cells $(\mathrm{p}<0.01$; Figure 2C).

Inhibition of DIDO1 in bladder cancer cells increases apoptosis. The effect of DIDO1 knockdown by DIDO1shRNAs on apoptosis was observed in T24 and 5637 cells. Apoptosis was measured by flow cytometry (Figure 3A). Apoptosis was significantly increased in cells expressing DIDO1-shRNAs compared with control cells $(\mathrm{p}<0.01$; Figure 3B). This indicated that DIDO1 might play an important role in apoptosis in bladder cancer cells.

To investigate whether apoptosis increases in a direct manner after DIDO1 knockdown, we determined the activity of cleaved-caspase-7 using the Cleaved-CaspaseGlu-7 assay kit. The result showed that the cleaved-caspase-7 activities were obviously increased after DIDO1 knockdown compared with controls (Figure 3C). Taken together, these results strongly suggested that apoptosis was significantly increased after DIDO1 knockdown.

Effect of DIDO1 silencing on stress and apoptosis in bladder cells. To explore the potential mechanisms by which DIDO1-silencing inhibits T24 cell growth and enhances apoptosis, the DIDO1-silencing triggered alterations in signaling molecules involved in stress and apoptosis were determined using PathScan Stress and Apoptosis Signaling Antibody Array Kit. Compared to shCtrl-treated T24 cells, depletion of DIDO1 significantly inhibited the phosphory- 
A

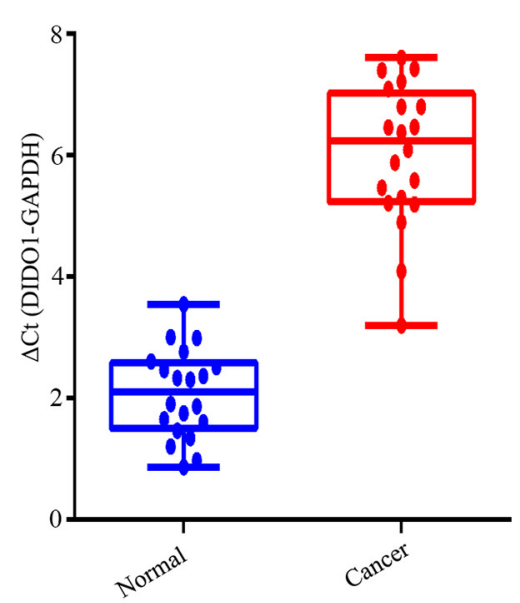

$\mathrm{D}$

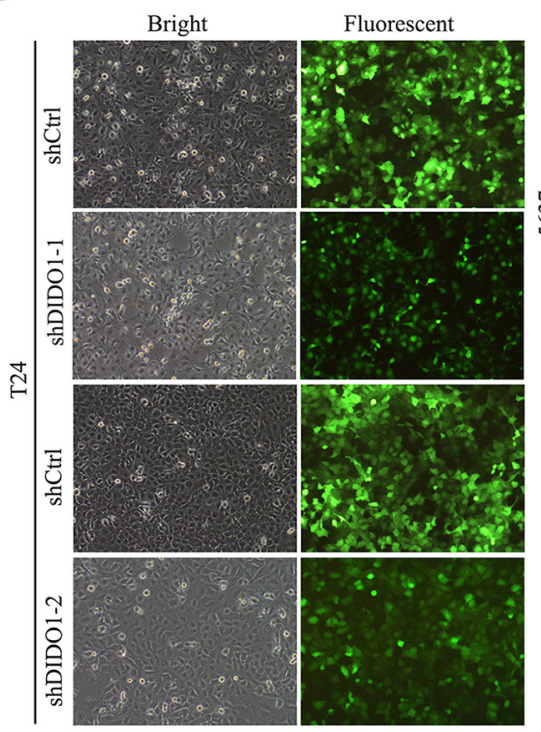

$\mathrm{B}$
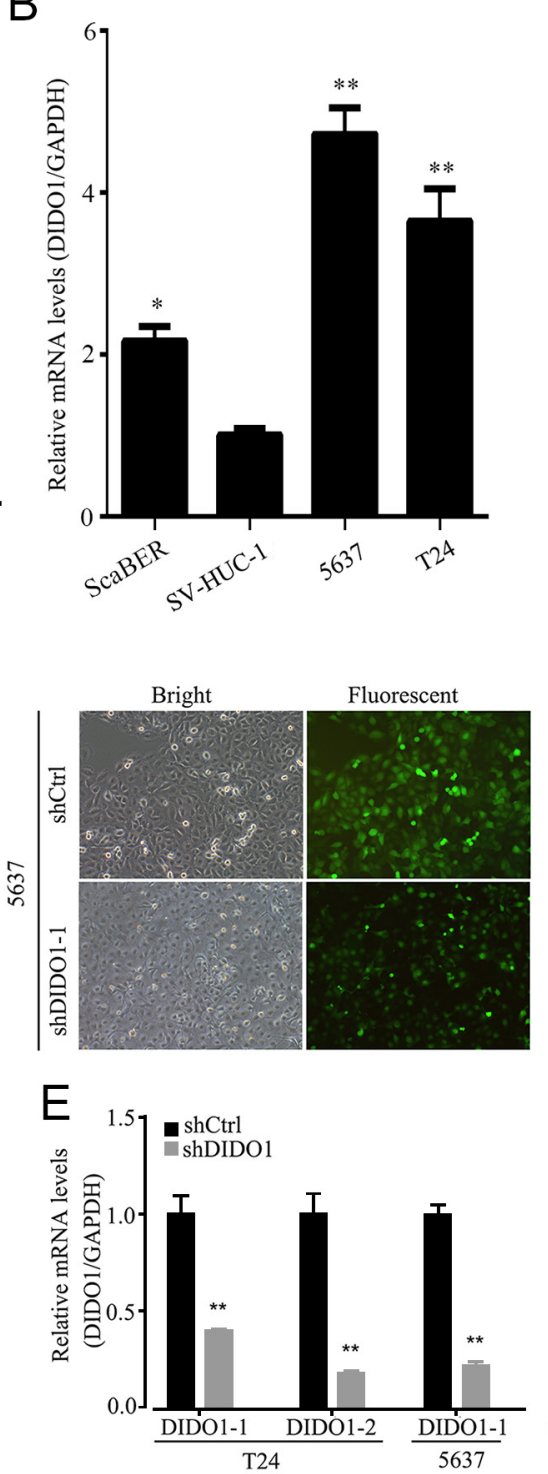

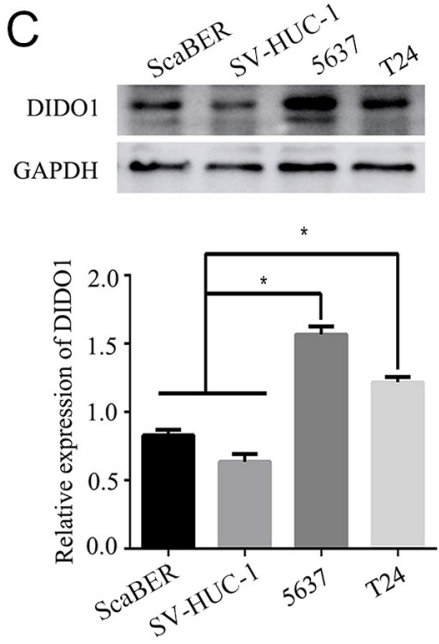

F

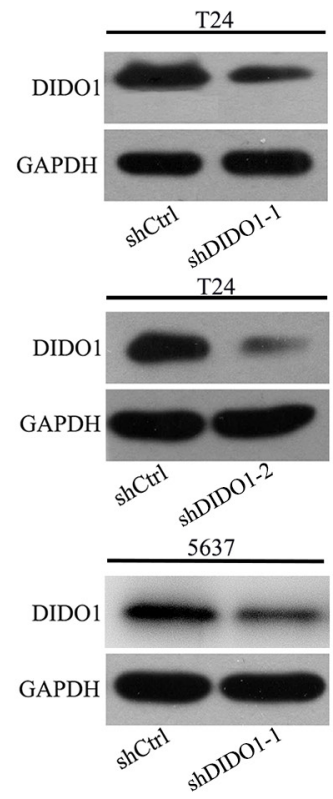

Figure 1. The expression of DIDO1 in bladder cancer tissue samples and bladder cell lines. A) The levels of DIDO1 mRNA in cancer and normal tissues were measured by qPCR $(\mathrm{p}<0.01)$. B) The level of DIDO1 mRNA was detected by qPCR in human bladder cancer cell lines T24, ScaBER, 5637, and human normal bladder epithelial cell line SV-HUC-1. C) The level of DIDO1 protein detected by western blotting in human bladder cancer cell lines T24, ScaBER, 5637, and human normal bladder epithelial cell line SV-HUC-1. The efficiency of DIDO1 knockdown was determined by fluorescence microscopy (D), RT-PCR (E), and western blot (F) in T24 and 5637 cells. ${ }^{*} \mathrm{p}<0.05,{ }^{* *} \mathrm{p}<0.01$ compared with control

lation of SAPK/JNK (Thr183/Try185), Chk1 (Ser345), Chk2 (Thr68), and eIF2 $\alpha$ (Ser51), as well as IkBa (Total), Survivin (Total), and $\alpha$-Tubulin (Total) (Figure 3D). The result of western blot also showed that knockdown of DIDO1 induced the decreased levels of $\mathrm{p}-\mathrm{JNK}, \mathrm{pChk} 1 / \mathrm{pChk} 2$, and increased the level of cleaved-caspase-7 (Figure 3E) which was consistent with that of PathScan Stress and Apoptosis Signaling Antibody Array Kit.

The addition of the JNK activator counteracted the effects of DIDO1-silencing on proliferation and apoptosis of bladder cancer cells. To verify whether JNK plays a role in maintaining DIDO1's effect on bladder cancer cells, we performed a rescue experiment. After the addition of JNK activator Anisomycin (Beyotime, Shanghai, China) in shCtrl or shDIDO1 treated T24 cells and incubation for 24 $\mathrm{h}$, cell proliferation and apoptosis were tested using MTT and TUNEL assay, respectively. The results showed that compared with the control, the addition of JNK activator promoted proliferation of T24 cells, and apoptosis of T24 cells was inhibited. The addition of JNK activator partially restored DIDO1-shRNA-induced inhibitory effect on cell proliferation, while the apoptosis of cells transfected with 
A

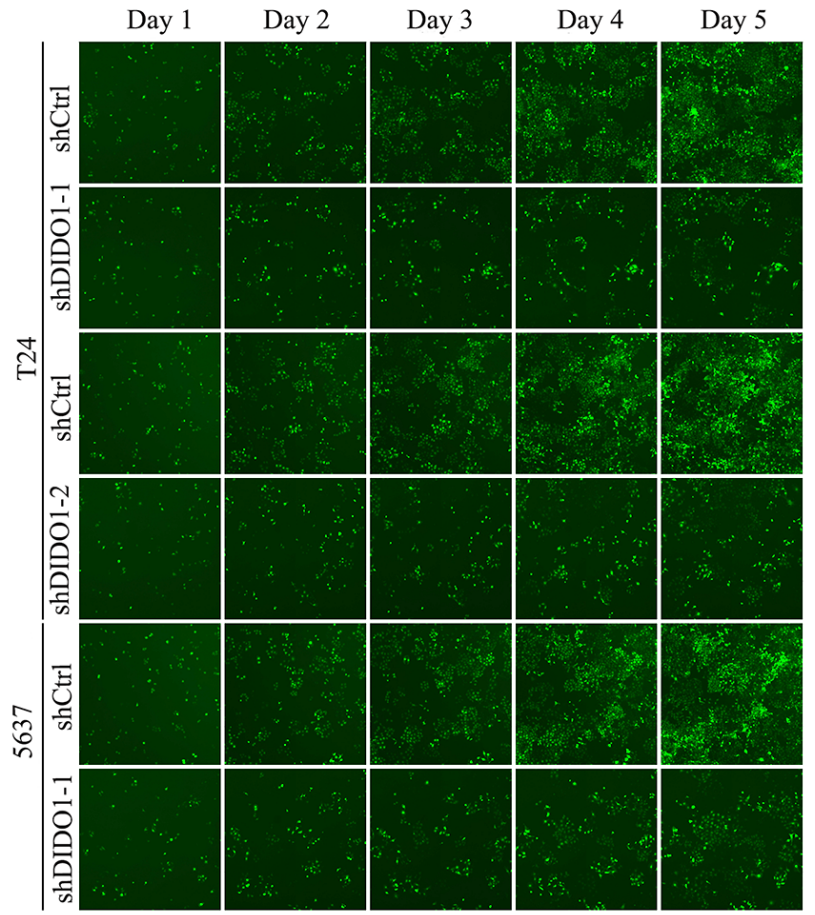

C

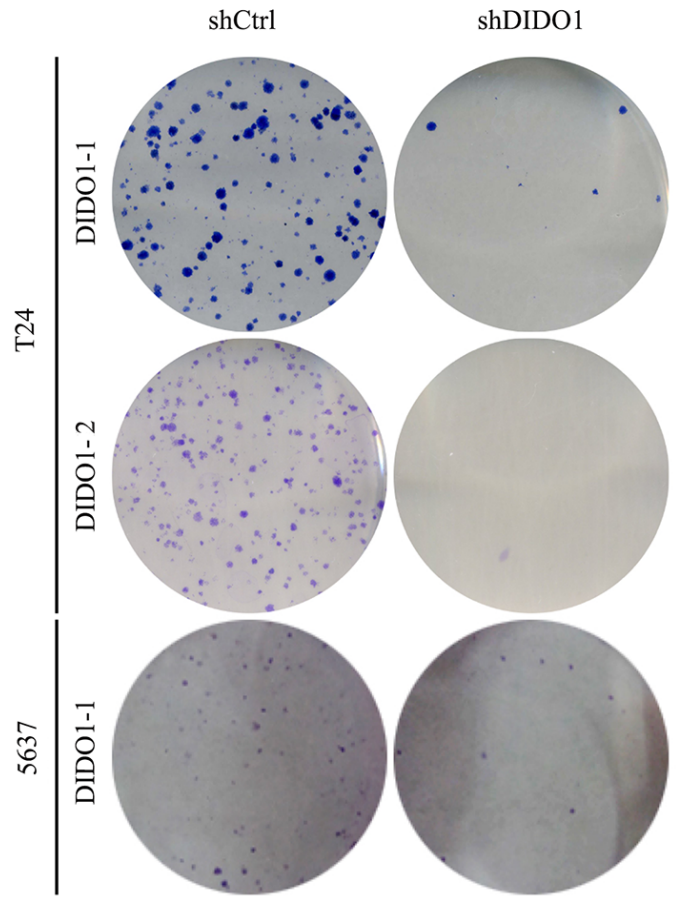

B
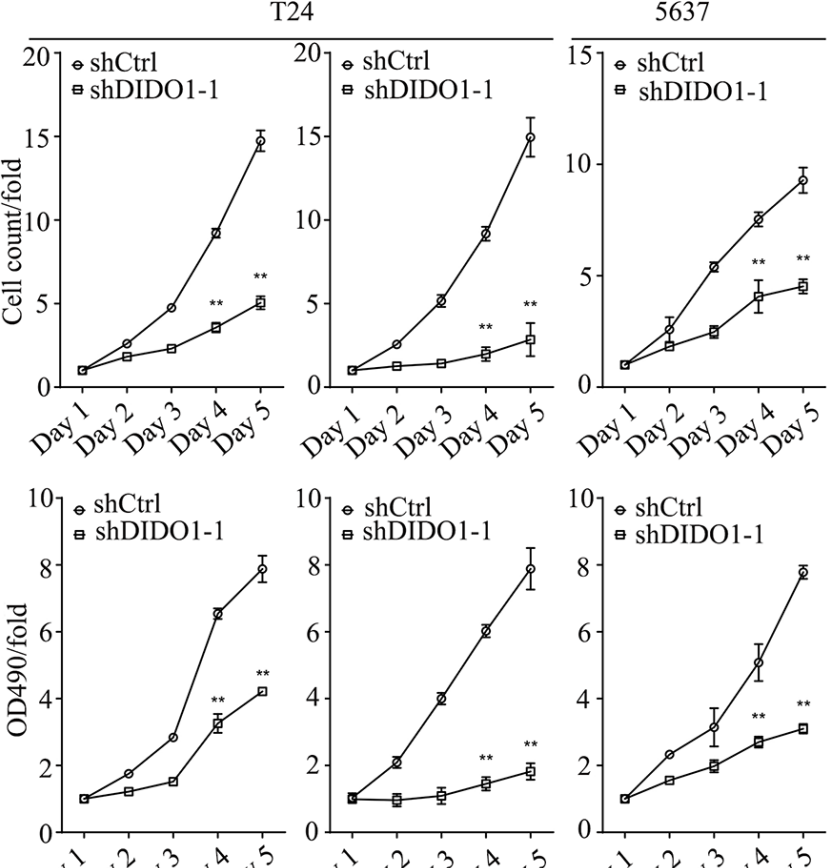

${ }^{10} 7 \bullet \operatorname{shCtrl}$

* shDIDO1-1

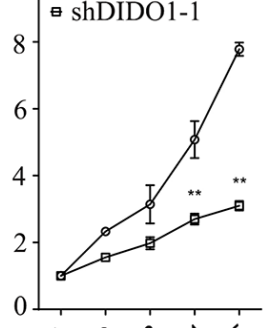

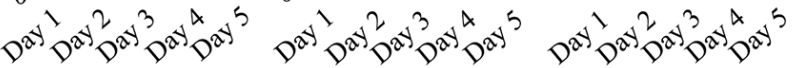

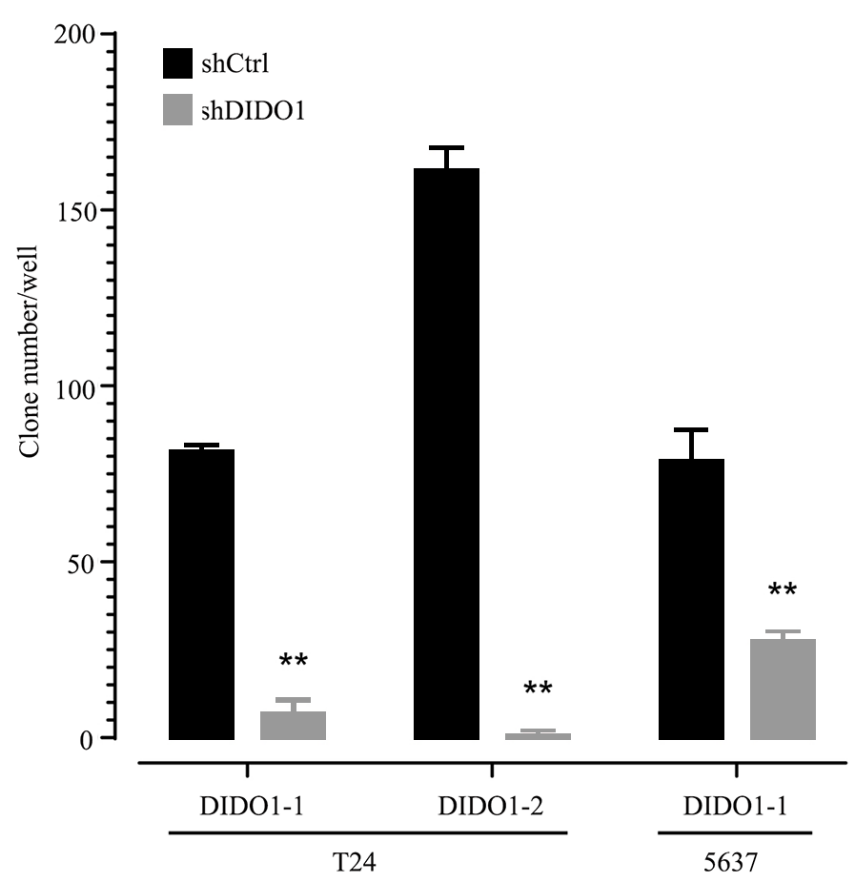

Figure 2. Effect of DIDO1 knockdown on proliferation and colony formation in bladder cancer cells. A) Representative images of cell growth of T24 and 5637 cells after DIDO1 knockdown taken using a fluorescence microscope $(\times 200)$. B) Cell proliferation rate was detected by Celigo assay and the viabilities of T24 and 5637 were detected by MTT assay after DIDO1 knockdown on the first five days. All experiments were performed with triples. C) The average number of colonies of T24 and 5637 cells in each well. ${ }^{* *} \mathrm{p}<0.01$ compared with control 
A

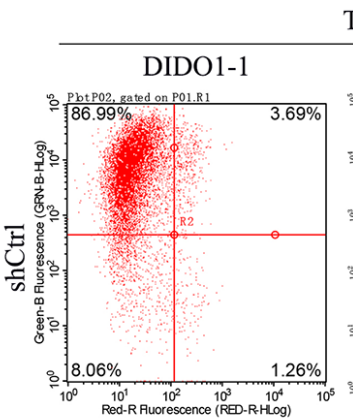

$\mathrm{T} 24$
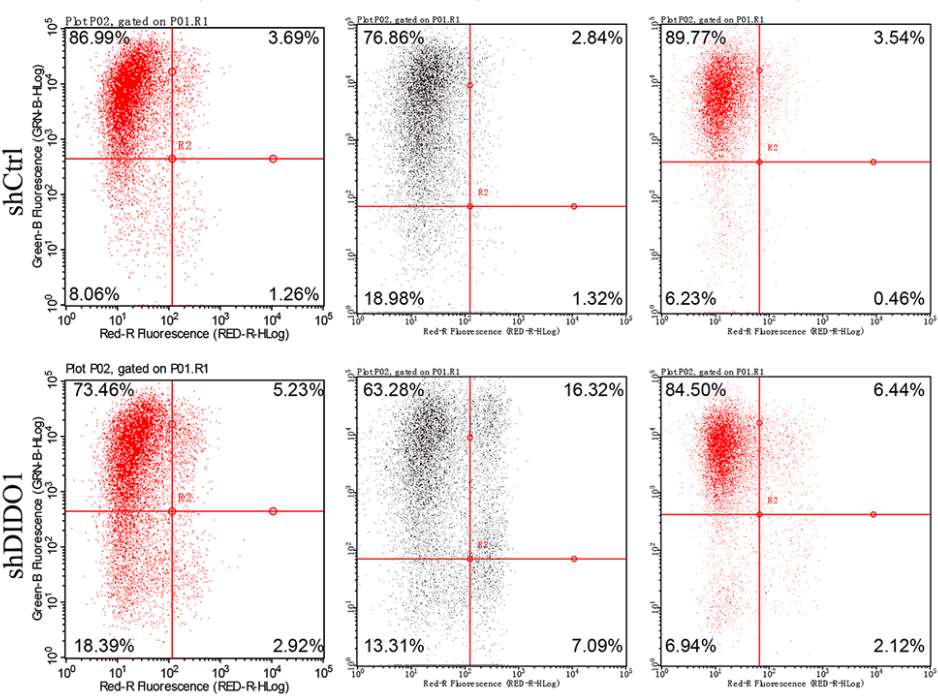

B

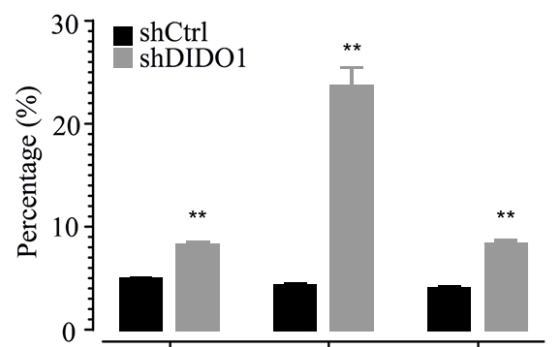

$\mathcal{C}$

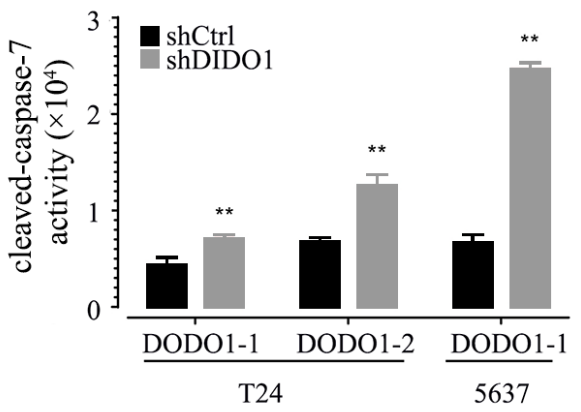

E

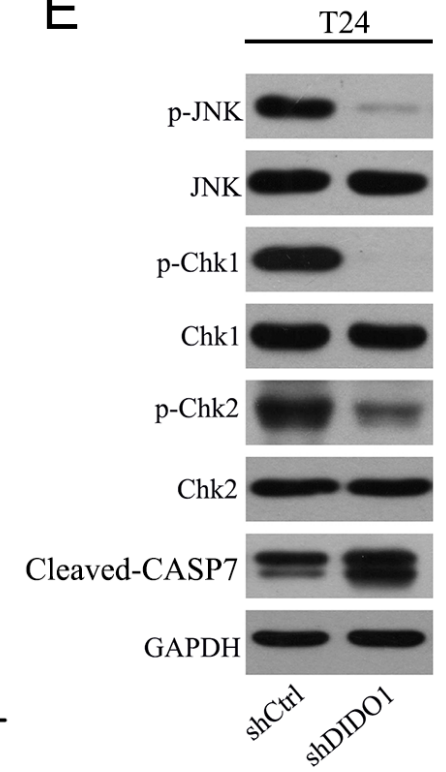

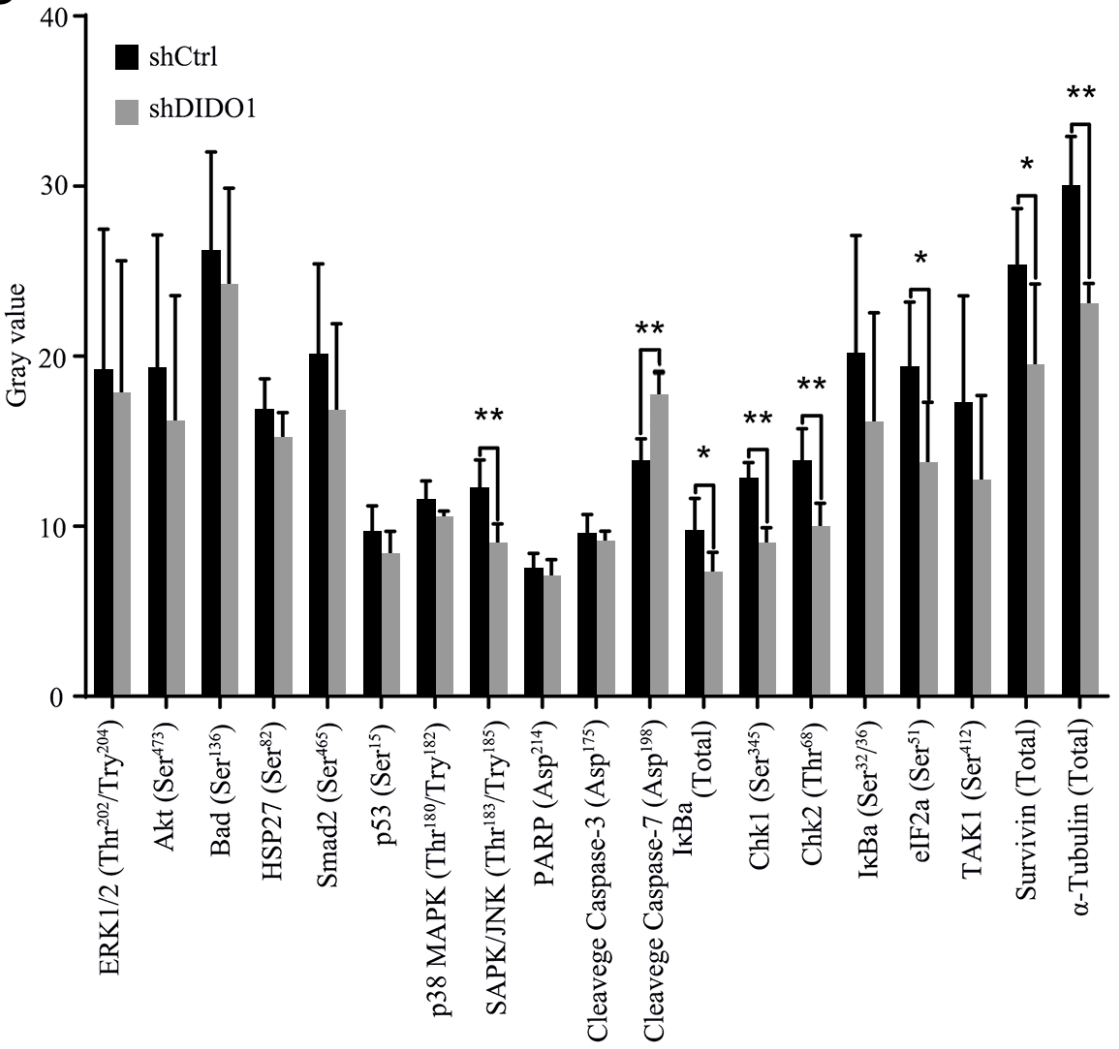

Figure 3. DIDO1-shRNA facilitated early apoptosis of T24 and 5637 cells. A) Representative images of cell death by flow cytometry. B) Changes of early apoptosis of cells expressing DIDO1-shRNA in T24 and 5637 cells. C) The relative ratio of cleaved-caspase-3/7 enzymatic activity was measured for the cell homogenates using the Cleaved-Caspase-Glo-7 assay kit. D) Chemiluminescent array image pixel intensity value of signaling molecules in T24 cells. E) Differentially expressed genes in D) were detected by western blot. Note: Gray value was quantified using array analysis software according to the image of the digital array slides. ${ }^{\star} \mathrm{p}<0.05,{ }^{\star *} \mathrm{p}<0.01$, compared with controls, respectively. 
DIDO1-shRNA was inhibited by JNK activator (Figure 4). The results above indicate that JNK plays an important role in DIDO1 knockdown related proliferation and apoptosis of bladder cancer cells.

DIDO1 knockdown inhibits tumor growth in vivo. Finally, to clarify the potential of targeting DIDO1 as a therapeutic approach for bladder cancer, nude mice were subcutaneously injected with cells transfected with either the
shDIDO1 or the shCtrl lentivirus. Five weeks after inoculation, tumors established from T24 cells stably transfected with shDIDO1 were smaller in size compared to the tumors from T24 cells stably transfected with the shCtrl vector (Figures 5A, 5B). Moreover, all mice injected with shDIDO1 transfected cells had smaller volumes of detectable implants 5 weeks after inoculation (Figures 5C-5E). This result confirmed that shDIDO1 suppressed tumor growth in vivo.

A

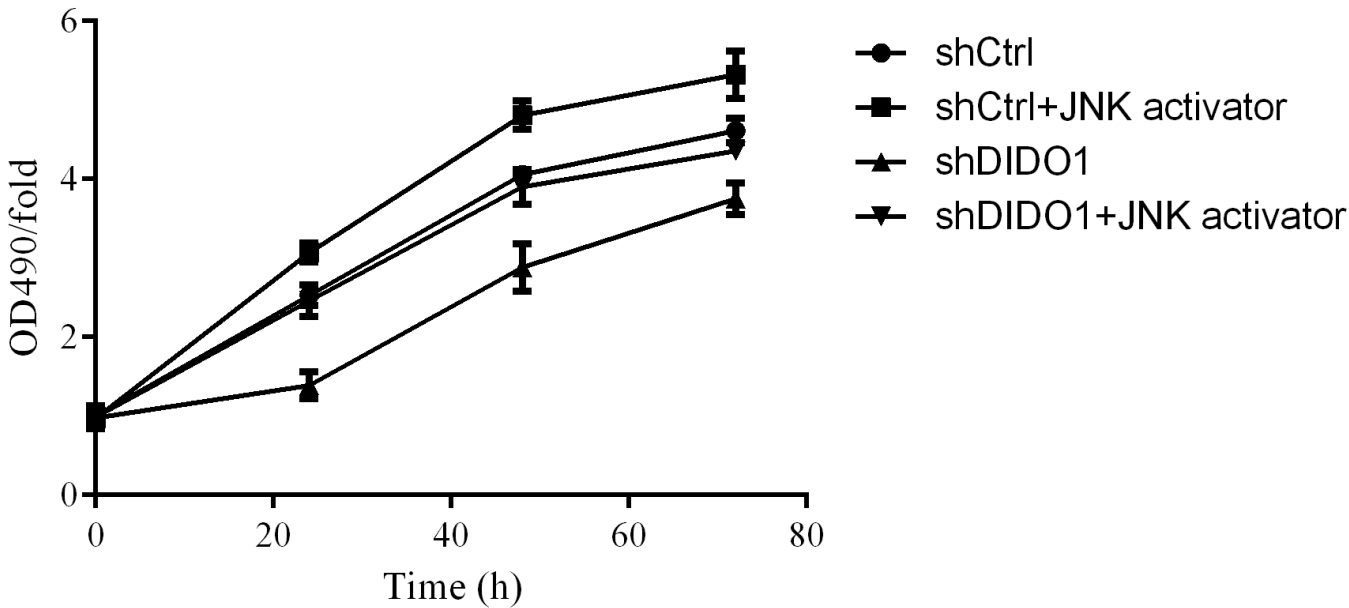

B

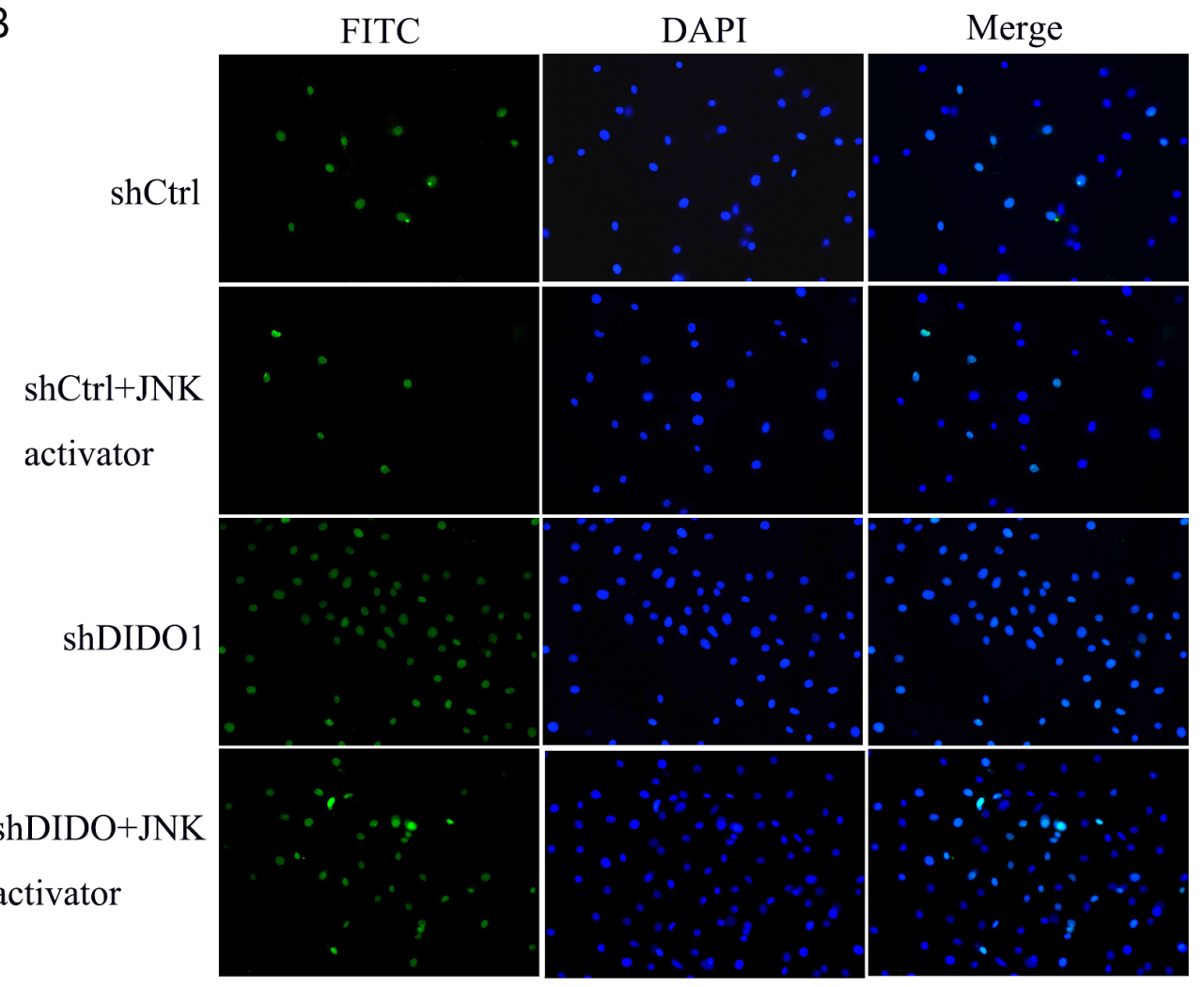

Figure 4. The effect of JNK on DIDO1 silencing-induced bladder cancer cells. A) The viability of T24 cells was detected by MTT assay after DIDO1shRNA and JNK activator processed. B) Cell apoptosis was tested using TUNEL assay in T24 cells by DIDO1-shRNA and JNK activator. 
These data indicated that targeting DIDO1 with shDIDO1 lentivirus could have an inhibitory effect in vivo on bladder cancer in which DIDO1 is overexpressed.

\section{Discussion}

Previous studies have shown that DIDO1 plays a critical role in apoptosis [9]. Overexpression of DIDO1 in cells promotes cell apoptosis without apoptotic stimuli and downregulation in chick limbs disrupts the limb development [9]. After apoptosis induced by stimuli such as IL-3 starvation and c-myc induction, DIDO1 translocates from the cytoplasm to the nucleus, followed by an appearance of apoptotic features such as caspase activation and nuclear disruption. Therefore, DIDO1 activation is an early step of the apoptotic process [10]. Apoptosis induced by DIDO1 can be inhibited by expression of $\mathrm{Bcl} 2$ which inhibits caspase activity [11-13]. This also suggests that DIDO1 is an upstream factor of the caspase cascade, and it plays a role in regulating apoptosis by initiating the mechanism at the transcriptional level. Reducing DIDO1 mRNA expression did not impact cell viability in CRC cell lines upon 5FU-induced cytotoxicity, which argues against a role of DIDO1 in causing chromosomal instability associated with apoptosis [14]. However, a different study found that overexpression of DIDO1 results in chromosomal instability [15].

A recent study indicated that DIDO1 was highly expressed in bladder cancer samples compared with normal tissues, and downregulation of DIDO1 suppressed anchorage-independent growth, and expression of DIDO1 mRNA is associated with chromosome $20 \mathrm{q}$ gain status in colorectal adenoma for carcinoma progression [16]. Furthermore, Braig et al. demonstrated that DIDO1 expression was upregulated in melanoma cell lines and tissues compared with normal melanocytes, and knockdown of DIDO1 expression reduced the attachment, migration, and invasion of melanoma cells [17]. This research is the first study examining DIDO1 expression and function in bladder cancer cells including T24, ScaBER, and 5637. Our results indicate that DIDO1 is expressed in all three bladder cancer cell lines, and the expression levels of DIDO1 in T24 and 5637 cells were higher than those in SV-HUC-1 and ScaBER cells. To further evaluate the function of DIDO1 in bladder cancer cell lines, T24 and 5637 cells expressing DIDO1-shRNAs and control lentivirus were
A

D

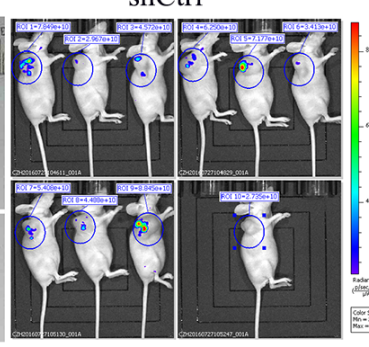

C

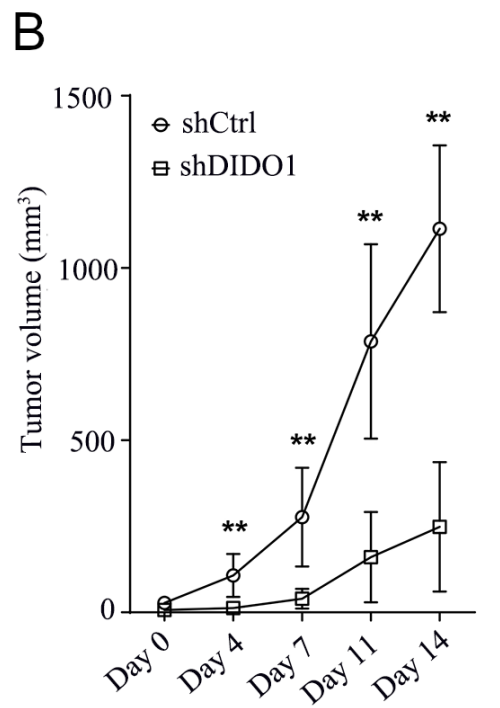

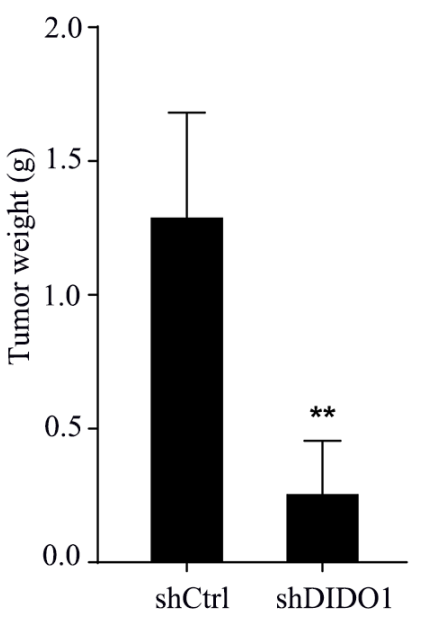

D

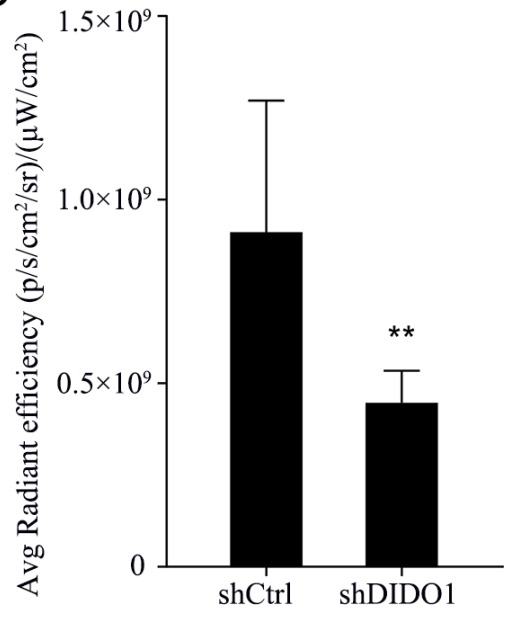

Figure 5. Tumor volume and weight detection. A) The presentative image of fluorescent density in tumors. B) Fluorescent density from (A) was quantified. C) The sizes of the T24 implant at 5 weeks after injection. D) The volume of the T24 implant at 5 weeks after injection. E) The average weight of tumors at 5 weeks after tumor cell injection, $n=10$. Note: The beginning of measurement for tumor volume and weight was referred to day 0 . ${ }^{\star *} p<0.01$ 
established. The expressions of DIDO1 mRNA and protein were significantly reduced in T24 and 5637 cells expressing DIDO1-shRNAs compared with control cells, ensuring the validity of our experiments.

DIDO1 was first discovered as a tumor suppressor, and some studies indicated that the two splice variants of DIDO1 are unnecessary for survival $[7,18]$. It has also been reported that knockdown of DIDO1 reduced cell colony formation and promoted apoptosis in melanoma cells [17]. The results of this research showed that knockdown of DIDO1 expression in T24 and 5637 cells reduces cell proliferation, suppresses cell colony formation, and augments apoptosis. Additionally, xenograft tumor studies also confirmed that DIDO1 knockdown inhibited the growth of the tumor. These results suggested that DIDO1 augments T24 and 5637 cell growth. Taken together, this information above suggests that DIDO1 may play a different role in various cancers, and further research is needed to elucidate the DIDO1 function.

In order to investigate the effect of DIDO1 knockdown in shDIDO1-transfected T24 cells, the stress and apoptosis profiles of various signaling molecules were evaluated. The data showed that DIDO1 knockdown significantly reduced the levels of phosphorylated SAPK/JNK (Thr183/Try185), Chk1 (Ser345), Chk2 (Thr68), and eIF2a (Ser51), as well as the expression levels of I $\mathrm{B} a$ (Total), Survivin (Total,) and $\alpha$-Tubulin (Total). The stress-activated protein kinases (SAPKs), also known as c-Jun amino-terminal kinases (JNKs), induce apoptosis by translocating to mitochondria with Bcl-xl interaction in response to DNA damage [19]. Due to the failure of repair, DNA damage results in cellular senescence or cell death [20]. As one of the effector caspases, caspase-7 (CASP7) cleaves important cellular substrates to accomplish apoptosis $[21,22]$. CASP7 is also activated during Fas- and mitochondria-induced apoptosis [22, 23]. Downregulation of CASP7 is frequently seen in several forms of cancer $[24,25]$. Phosphorylated checkpoint kinase $1 / 2(\mathrm{Chk} 1 / 2)$ activates the replication stress response, which is characterized by stalled replication forks [26] and contributes to cancer cells senescence [27]. The present study indicates that the increased apoptosis rate of 5637 cells due to DIDO1 silencing may result in decreased activation of SAPK/JNK and I $\kappa \mathrm{B} \alpha$, which is responsible for accelerating protein synthesis of cleaved-CASP7, Chk1/2, eIF2 $\alpha$, Survivin, and $\alpha$-tubulin. Moreover, the result of western blot showed that DIDO1 knockdown induced the decreased expressions of phosphorylated JNK and Chk1/Chk2. However, cleavedCAPS7 was significantly increased. Besides, increasing evidence demonstrates that DIDO1 isoform augments the onset of apoptosis in vitro [6]. In contrast, DIDO3 isoform might be one of the tumor suppressors [7]. Some research papers show that the reduction of SAPK/JNK can enhance cell survival $[28,29]$. However, some studies have indicated that inhibition of SAPK/JNK can promote cell apoptosis $[30,31]$. In this study, we found that DIDO1 knockdown decreased the phosphorylation of SAPK/JNK to inhibit proliferation and promote apoptosis. In addition to that, the JNK activator partially restored the effect of DIDO1 silencing on bladder cancer cells. The possible reason leading to this contradiction may relate to the target of DIDO1 knockdown because in the present study, the process of DIDO1 knockdown targets all three isoforms of DIDO1. Therefore, the detailed mechanism of action of pro-apoptosis due to DIDO1 knockdown is currently unclear and needs to be further investigated.

In conclusion, this study focused on the roles of DIDO1 in bladder cancer cells. We found that knockdown of DIDO1 by lentivirus-mediated shRNA decreases the rate of proliferation, reduces cell colony formation, inhibits xenograft tumor growth, and increases apoptosis. The possible mechanisms by which DIDO1 knockdown inhibits bladder cancer cell growth and promotes apoptosis may be related to the downregulation of SAPK/JNK and Chk1/2 and upregulation of cleaved-caspase-7. These findings suggest that DIDO1 may be a potential target for the treatment of bladder cancer. Further studies will detect the effect of DIDO1 on migration and invasion of bladder cancer cells as a supplement of the present study.

Acknowledgments: This work was financed by the Natural Science Research Project of Colleges and Universities in Anhui Province (No. KJ2018A0999) and Science and Technology Development Foundation of Bengbu Medical College (BYKF1778).

\section{References}

[1] GRIFFITHS TRL. Current perspectives in bladder cancer management. Int J Clin Pract 2013; 67: 435-448. https://doi. org/10.1111/ijcp.12075

[2] ISSAQ HJ, NATIV O, WAYBRIGHT T, LUKE B, VEENSTRA TD et al. Detection of bladder cancer in human urine by metabolomic profiling using high performance liquid chromatography/mass spectrometry. J Urol 2008; 179 : 2422-2426. https://doi.org/10.1016/j.juro.2008.01.084

[3] SANLI O, DOBRUCH J, KNOWLES MA, BURGER M, ALEMOZAFFAR $M$ et al. Bladder cancer. Nat Rev Dis Primers 2017; 3: 17022. https://doi.org/10.1038/nrdp.2017.22

[4] JEONG IG, PARK J, SONG K, RO JY, SONG C et al. Comparison of 2002 TNM nodal status with lymph node density in node-positive patients after radical cystectomy for bladder cancer: analysis by the number of lymph nodes removed. Urol Oncol 2011; 29: 199-204. https://doi.org/10.1016/j. urolonc.2009.04.006

[5] APOLO AB, MILOWSKY M, BAJORIN DF. Clinical states model for biomarkers in bladder cancer. Future Oncol 2009; 5: 977-992. https://doi.org/10.2217/fon.09.57

[6] GARCÍA-DOMINGO D, LEONARDO E, GRANDIEN A, MARTÍNEZ P, ALBAR JP et al. DIO-1 is a gene involved in onset of apoptosis in vitro, whose misexpression disrupts limb development. Proc Natl Acad Sci U S A 1999; 96: 79927997. https://doi.org/10.1073/pnas.96.14.7992 
[7] AGNES F, CAMPANERO MR, ESTHER L, CRIADO LM, FLORES JM et al. Dido gene expression alterations are implicated in the induction of hematological myeloid neoplasms. J Clin Invest 2005; 115: 2351-2362. https://doi.org/10.1172/ JCI24177

[8] PFAFFL MW, HORGAN GW, DEMPFLE L. Relative expression software tool (REST) for group-wise comparison and statistical analysis of relative expression results in real-time PCR. Nucleic Acids Res 2002; 30: e36. https://doi. org/10.1093/nar/30.9.e36

[9] LIU Y, KIM H, LIANG J, LU W, OUYANG B et al. The death-inducer obliterator 1 (Dido1) gene regulates embryonic stem cell self-renewal. J Biol Chem ; 289: 4778-4786. https://doi.org/10.1074/jbc.M113.486290

[10] GARCIA-DOMINGO D, RAMIREZ D, GONZALEZ DE BUITRAGO G, MARTINEZ AC. Death inducer-obliterator 1 triggers apoptosis after nuclear translocation and caspase upregulation. Mol Cell Biol 2003; 23: 3216-3225. https://doi. org/10.1128/mcb.23.9.3216-3225.2003

[11] CEKANOVA M, FERNANDO RI, SIRIWARDHANA N, SUKHTHANKAR M, DE LA PARRA C et al. BCL-2 family protein, $\mathrm{BAD}$ is down-regulated in breast cancer and inhibits cell invasion. Exp Cell Res 2015; 331: 1-10. https://doi. org/10.1016/j.yexcr.2014.11.016

[12] BELKIN AD. [The content of protein regulators of apoptosis $\mathrm{Bcl}-2$ and bad in regional lymph nodes of the liver under the influence of $50 \mathrm{~Hz}$ a magnetic field]. Gig Sanit 2015; 94: 112-114.

[13] HASSANEIN EHM, SHALKAMI AS, KHALAF MM, MOHAMED WR, HEMEIDA RAM. The impact of Keap1/Nrf2, P38MAPK/NF-kappaB and Bax/Bcl2/caspase-3 signaling pathways in the protective effects of berberine against methotrexate-induced nephrotoxicity. Biomed Pharmacother 2019; 109: 47-56. https://doi.org/10.1016/j.biopha.2018.10.088

[14] TRACHANA V, VAN WELY KH, GUERRERO AA, FUTTERER A, MARTINEZ AC. Dido disruption leads to centrosome amplification and mitotic checkpoint defects compromising chromosome stability. Proc Natl Acad Sci U S A 2007; 104: 2691-2696. https://doi.org/10.1073/pnas.0611132104

[15] ROJAS AM, SANCHEZ-PULIDO L, FUTTERER A, VAN WELY KH, MARTINEZ AC et al. Death inducer obliterator protein 1 in the context of DNA regulation. Sequence analyses of distant homologues point to a novel functional role. FEBS J 2005; 272: 3505-3511. https://doi.org/10.1111/ j.1742-4658.2005.04759.x

[16] SILLARS-HARDEBOL AH, BEATRIZ C, BELIEN JAM, MEIKE DW, DIEMEN DV et al. CSE1L, DIDO1 and RBM39 in colorectal adenoma to carcinoma progression. Cell Oncol (Dordr) 2012; 35: 293-300. https://doi.org/10.1007/s13402012-0088-2

[17] BRAIG S, BOSSERHOFF AK. Death inducer-obliterator 1 (Dido1) is a BMP target gene and promotes BMP-induced melanoma progression. Oncogene 2013; 32: 837-848. https://doi.org/10.1038/onc.2012.115

[18] TRACHANA V, VAN WELY KHM, GUERRERO AA, FÜTTERER A, MARTÍNEZ-A C. Dido disruption leads to centrosome amplification and mitotic checkpoint defects compromising chromosome stability. Proc Natl Acad Sci U S A 2007; 104: 2691-2696. https://doi.org/10.1073/ pnas.0611132104
[19] KHARBANDA S, SAXENA S, YOSHIDA K, PANDEY P, KANEKI M et al. Translocation of SAPK/JNK to mitochondria and interaction with $\mathrm{Bcl}-\mathrm{x}(\mathrm{L})$ in response to DNA damage. J Biol Chem 2000; 275: 322-327. https://doi.org/10.1074/ jbc.275.1.322

[20] ZHOU BB, ELLEDGE SJ. The DNA damage response: putting checkpoints in perspective. Nature 2000; 408: 433-439. https://doi.org/10.1038/35044005

[21] SINGH N., BOSE K. Apoptosis: Pathways, Molecules and Beyond. In: Bose K. (eds) Proteases in Apoptosis: Pathways, Protocols and Translational Advances. Springer, Cham 2015 https://doi.org/10.1007/978-3-319-19497-4_1

[22] HIRATA H, TAKAHASHI A, KOBAYASHI S, YONEHARA $\mathrm{S}$, SAWAI $\mathrm{H}$ et al. Caspases are activated in a branched protease cascade and control distinct downstream processes in Fas-induced apoptosis. J Exp Med 1998; 187: 587-600. https://doi.org/10.1084/jem.187.4.587

[23] SLEE EA, HARTE MT, KLUCK RM, WOLF BB, CASIANO $\mathrm{CA}$ et al. Ordering the cytochrome c-initiated caspase cascade: hierarchical activation of caspases- $2,-3,-6,-7,-8$, and -10 in a caspase-9-dependent manner. J Cell Biol 1999; 144: 281-292. https://doi.org/10.1083/jcb.144.2.281

[24] PALMERINI F, DEVILARD E, JARRY A, BIRG F, XERRI L. Caspase 7 downregulation as an immunohistochemical marker of colonic carcinoma. Hum Pathol 2001; 32: 461467. https://doi.org/10.1053/hupa.2001.24328

[25] SOUNG YH, LEE JW, KIM HS, PARK WS, KIM SY et al. Inactivating mutations of CASPASE-7 gene in human cancers. Oncogene 2003; 22: 8048-8052. https://doi.org/10.1038/ sj.onc. 1206727

[26] SMITH J, THO LM, XU N, GILLESPIE DA. Chapter 3 The ATM-Chk2 and ATR-Chk1 Pathways in DNA Damage Signaling and Cancer. Adv Cancer Res 2010; 108: 73-112. https://doi.org/10.1016/B978-0-12-380888-2.00003-0

[27] LEE H, KIM Y, JEONG JH, RYU JH, KIM WY. ATM/CHK/ p53 Pathway Dependent Chemopreventive and Therapeutic Activity on Lung Cancer by Pterostilbene. PLoS One 2016; 11: e0162335. https://doi.org/10.1371/journal.pone.0162335

[28] RAJMANI RS, GANDHAM RK, GUPTA SK, SAHOO AP, SINGH PK et al. HN Protein of Newcastle Disease Virus Induces Apoptosis Through SAPK/JNK Pathway. Appl Biochem Biotechnol 2015; 177: 940-956. https://doi. org/10.1007/s12010-015-1788-7

[29] VETHAKANRAJ HS, SESURAJAN BP, PADMANABAN VP, JAYAPRAKASAM M, MURALI $S$ et al. Anticancer effect of acid ceramidase inhibitor ceranib-2 in human breast cancer cell lines MCF-7, MDA MB-231 by the activation of SAPK/JNK, p38 MAPK apoptotic pathways, inhibition of the Akt pathway, downregulation of ERa Anticancer Drugs 2018; 29: 50-60. https://doi.org/10.1097/CAD.0000000000000566

[30] LIU J, LIN A. Role of JNK activation in apoptosis: a double-edged sword. Cell Res 2005; 15: 36-42. https://doi. org/10.1038/sj.cr.7290262

[31] LIN A. Activation of the JNK signaling pathway: breaking the brake on apoptosis. Bioessays 2003; 25: 17-24. https:// doi.org/10.1002/bies.10204 